\title{
RETHINKING THE BUILDING ENVELOPE: BUILDING INTEGRATED ENERGY POSITIVE SOLUTIONS
}

\author{
JOANNA CLARKE ${ }^{1}$, JOHN LITTLEWOOD ${ }^{2}$, PAUL WILGEROTH $^{2} \&$ PAUL JONES $^{1}$ \\ ${ }^{1}$ SPECIFIC, Swansea University, Wales, UK \\ ${ }^{2}$ Cardiff School of Art and Design, Cardiff, Wales, UK
}

\begin{abstract}
This paper discusses information from a research project investigating a new approach to designing energy positive buildings that integrate renewable energy generation into the building fabric. Such buildings can help reduce energy consumption and associated carbon emissions, alleviating fuel poverty and lessening the need for costly grid upgrades. The main purpose of this study is to highlight the current status of the UK construction industry and the need for improvements, which have been documented over the years. Several enablers for the construction industry to change are identified, including collaborative procurement methods, building information modelling (BIM), innovation and energy positive buildings. The key findings from the review provide evidence that the energy positive solutions put forward in this research project, linking collaboration, innovation and buildings with reduced energy use and carbon emissions, could be used to improve the overall performance of the construction industry. This provides a good knowledge base for the next phase of the research, which includes interviews and workshops with construction industry stakeholders to further identify the challenges, benefits and drawbacks of the potential building integrated energy positive solutions. The combined body of information gleaned from this literature review, the feedback from construction industry stakeholders, and case studies of energy positive buildings designed by the first author, will be used to aid the development of the proposed outcomes of the research project, which will include a continuous improvement tool, the case studies themselves and the development of an innovation portal. Keywords: energy positive, innovation in construction, collaborative procurement.
\end{abstract}

\section{INTRODUCTION}

The first author is undertaking research associated with her role at the SPECIFIC Innovation and Knowledge Centre (IKC), UK, in the context to their work on energy positive buildings [1]. Three energy positive building projects designed by the first author and one designed by others will be used as case studies in the research project, see Fig. 1 below.

This paper will examine existing literature on collaborative tools, techniques and procurement methods for the delivery of a sustainable built environment, including how innovation and change have been addressed in the construction industry to date (2018) and the challenges experienced. Challenges the project will address are focused around the need to reduce the amount of energy consumed by the built environment and the consequent carbon emissions that are harmful to the natural environment. The building and construction sector are responsible for approximately $30 \%$ of all global energy consumption and the associated greenhouse gases [2], suggesting a solution to address this is necessary and timely. Continuous improvement tools developed for construction and other industries will be subject to further investigations as part of the overall research project, to determine whether there is any evidence to suggest they could be used to encourage a more cohesive environment for the delivery of energy positive buildings. This work does not form part of this paper. 


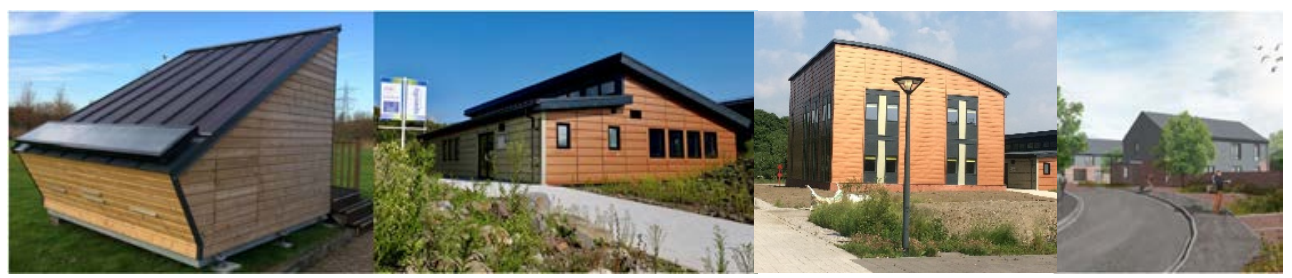

Figure 1: Case Studies - Active Pod, Active Classroom, Active Office and Active Homes.

\section{THE NEED FOR CHANGE}

The need for the UK construction industry to improve performance has been widely reported and two of the main reports on the state of the industry, "Constructing the Team" [3] and "Rethinking Construction" [4], both commissioned by the UK Government, are cited in many of the papers reviewed in this study, even those where research is non-UK focused [5]-[16], emphasising their significance to the industry.

Egan [4], who chaired the Construction Task Force set up by the then Deputy Prime Minister, John Prescott, in 1997, suggested the construction industry look to other industries, such as manufacturing in terms of what has driven them to achieve radical changes and better processes and identified some key drivers of change that have worked and are applicable to the construction industry. These include: Committed Leadership; A focus on the customer; Integrate the process and team around the product; A quality driven agenda; and Commitment to people (ibid). However, ten years later in 2009, little improvement to the industry had been made and another industry expert produced a report entitled "Never Waste a Good Crisis" [17], which found the suggested approach to apply manufacturing experience to an industry as different as construction was deemed unrealistic by the construction industry professionals questioned. Twenty years later, in 2018, the drivers suggested by Egan [4] are still relevant and not fully addressed.

Wolstenholme [17] further proposed that one of the greatest challenges to the industry was delivering a low carbon economy through the built environment. The energy positive case studies used in this research project (shown in Fig. 1 above) will demonstrate how this might be possible.

\section{ENABLERS OF CHANGE}

\subsection{Collaborative procurement}

Collaborative procurement is described as "...an effective way for more than one client, contractor, consultant or supplier to join together to procure work, services, materials or goods, share expertise, promote efficiency and deliver value for money savings in the delivery of a project..." [18].

The implications of procurement on the delivery of energy efficient buildings and the need to move away from cost-driven procurement methods is discussed by Alencastro et al. [19]. They discuss how, although Design and Build (D\&B), for example, was established to encourage and enable better value for money, it is more often used to drive down costs, as also found by Eriksson [20]. Their research found that a collaborative method of procurement is essential to enable the inclusion of energy performance targets as a fundamental objective at an early stage in the project (ibid). 
A study of the Australian construction industry [10] discussed how a no-blame culture can enable collaboration and promote innovative thinking. Within the Australasian Project Alliance procurement form referred to in the study, a "no-blame" behavioural contract clause was added to demand behaviours that result in a collaborative culture change and beneficial innovation, with all stakeholders having equal responsibilities.

Lloyd-Walker et al. [10] state that Design and Construct contracts can aid the use of innovation to improve value for money. They also mention an increased popularity in partnering arrangements, although evidence from the UK construction industry in 2015 found only 5\% of contracts used were Project Partnering Contract (PPC) 2000 and 3\% Joint Contracts Tribunal-Constructing Excellence (JCT-CE) [21], the two main forms of UK partnering contracts. Lloyd-Walker et al. [10] cite Dulaimi et al. [22] who reference the Singapore Governments C21 Report, which found that fragmentation and lack of integration within the construction industry has reduced productivity and that "creativity, quality and work innovation needed to be rewarded in order to promote innovation". This is happening in the UK through schemes such as the Welsh Government Innovative Housing Programme [23], and Transforming Construction [24], both of which encourage innovative ways to improve construction and deliver better value for money for new buildings.

Kilinc et al. [25] also acknowledge D\&B procurement as providing an opportunity to achieve innovation in the delivered project. Conversely, Eriksson [20] found that use of D\&B contracts can hinder innovation due to the lack of joint problem solving between designers and contractors as the design is complete before the contractor is involved, resulting in a lack of holistic design and construction. This was not the case when delivering the energy positive case studies referred to in this project, where D\&B aided the collaborative approach and use of innovative technologies, as described by Kilinc et al. [25].

Naoum and Egbu [26] review procurement methods in relation to innovation and technology, supply chain, lean construction, buildability, sustainability and value management. Their research concludes that the usual criteria used by clients when assessing tenders of time, cost and quality, are too simplistic for today's complex construction projects (ibid). However, in the first author's experience, these criteria are still the main factors determining procurement decisions. Naoum and Egbu [26] reference Ball and Fortune [5] who found that embracing sustainable construction will facilitate a change towards the use of partnering as a procurement process. After discussing how breaking the fragmented approach of the traditional route and encouraging cooperation through an integrated method of procurement to improve value of a project, Naoum and Egbu [26] conclude that, as clients and their project teams experience the benefits achieved through a more collaborative approach, a more integrated industry, where continuous improvement through team integration is seen as critical, will emerge (ibid). For the construction industry to embrace this, it needs to welcome "change" and allow innovative procurement methods to grow. The change needs to be mainly client-driven, with support from the rest of the project team (ibid). However, the Latham Report [3], advocating partnering and collaborative working, was written 24 years before 2018, and the uptake has been slow since this date. Challender et al. [8] suggest that the economic climate of austerity in 2013 significantly impacted on the trust element of collaborative procurement, which could explain the slow uptake. The perception that partnering is expensive has led to a return to competitive practices focusing on a shortterm perspective of securing lowest price, but they suggest Building Information Modelling (BIM), as described in Section 4.2, could help revive collaborative working (ibid).

In conducting research into partnering arrangements and gaining contractor's views, Eriksson [20] found that clients and contractors viewed partnering positively, particularly for large complex projects with high uncertainty, and it worked well when a collaborative culture 
was created amongst the project team. Eriksson and Westerberg [27] had previously discussed the positive effect collaborative procurement has on project performance, including cost, time, quality, environmental impact, work environment and innovation, with client leadership, as found by Egan [4].

Ey et al. [9] expand on Eriksson and Westerberg's [27] research to investigate barriers and challenges of collaborative procurement which they state is about "striking organisational synergies within a construction project team to reduce barriers to innovation and facilitate a cooperative project delivery". The main human-related barriers found were trust, communication, understanding of collaborators, cultural differences and relationships, while the main commercial-related barrier was commercial pressures, specifically the complexities of the commercial and contractual frameworks required to support collaboration [9]. The study concludes by reporting that while collaborative procurement has the potential to address some of the inherent difficulties facing the construction industry, there are barriers and challenges to the success, which are difficult to address (ibid). The case studies used in this project aim to tackle these challenges and remove some of the barriers.

\subsection{Building Information Modelling (BIM)}

The concept of BIM was first discussed as far back as 1962 by Douglas C. Englebart [28] but became mainstreamed within the UK construction industry in 2011 to encourage collaborative working practices to deliver construction projects by getting people and information working together effectively and efficiently through defined processes and technology [29].

Shibeika and Harty [30] examine how one company adopted digital innovation. To do this, they use diffusion of innovations (DOI) theory, which examines how new ideas move through a social system, to investigate how the innovation could change a complex firm, also applicable to the wider industry. The authors begin by explaining the key role of BIM in aiding the development of the construction industry. They recognise the complexity of the construction industry, which can stifle the diffusion of new technologies and practices and also the fact that organisations within the construction industry are constantly faced with changes, as the industry evolves and with the varied nature of each individual building project (ibid), concurring with research by Loosemore and Richard [11] and Matinaro and Liu [31]. This can make it more difficult for momentous changes to be diffused throughout the industry, which is fast moving and involves many changing factors.

While procurement routes (such as partnering and frameworks) and systems (such as BIM) exist to enable collaboration in construction projects, research studied within this paper suggests it is easier to implement these on large projects. Edie.Insight [32] also found that sustainable development is more likely to be driven by larger-sized construction companies. However, $99 \%$ of UK construction contracting businesses are small or medium enterprises (SMEs), which is of significant concern to the industry [32]. In a survey carried out by Edie.Insight, respondents were asked to identify the three most significant sustainability investment areas for their organisation during 2017/18 - only $33.33 \%$ identified "sustainable product design/innovation", which suggests it is not high on their agenda, possibly since it is not always in their control and needs to be driven by the client (ibid). Alwan et al. [33] also suggest that the proportion of small firms (up to 59 employees) making up the industry is one of the cultural challenges to sustainability within the construction sector. A large proportion of responsibility for reducing negative qualities of the industry lie with small companies. The proportion of small companies also leads to a low level of investment in training, education, innovation and research, resulting in most building personnel having only basic knowledge 
of global consequences of construction waste, pollution and emissions (ibid). The first author has come across one example of a small UK practice of five full-time staff, Constructive Thinking, that utilises BIM effectively for collaborative working even on small projects [34].

\subsection{Innovation}

Whilst Egan [4] suggested the construction industry learns from the manufacturing industry, Salem et al. [35] cite the main features of the construction industry that differ from manufacturing as: on-site production; one-of-a-kind projects; and complexity; the combined effect of which is uncertainty throughout the whole project.

Shibeika and Harty [30] suggest that use of DOI theory is perhaps too linear to deal with the complexities of construction and look to the work of Peansupap and Walker [36], who suggest that change management and social network analysis may be more appropriate. DOI and the non-collaborative, blame culture, are considered by Ajayi et al. [37] when examining the cultural change needed in the UK construction industry to deal with reducing waste to landfill. Ajayi et al. [37] found that organisational culture determines employees' readiness for innovation as well as their strategy and approach to innovation. Difficulties of adopting innovation in construction stem from the complex nature of the industry and its reliance on casual employment of labour force, i.e. it is not as stable as the manufacturing industry. The fact that designers and contractors usually work independent of one another adds to the difficulties, although this is addressed through collaborative working, enabled through partnering and frameworks (ibid), as illustrated by the case studies forming one of the outputs of this research project. Matinaro and Liu [31] discuss how a cultural transition to more innovative thinking in the construction industry can impact on sustainability, proposing that leadership is required to develop a culture towards change as also suggested by Kotter [38]. This is further discussed by Mousa [39] who uses Kotter's [38] eight-step model for change to consider an approach to transforming to sustainable construction in a developing country. Costs are recognised as a major barrier to the widespread use of sustainable materials due to higher upfront capital costs and a disregard for life cycle and performance, which is also described in the research work of Darko and Chan [40].

Matinaro and Liu [31] recognise that challenges of innovation in the construction industry are in part due to the diverse and multi-levelled nature of the industry and the fact that it is a project-based industry, concurring with Ajayi et al. [37]. Whilst the industry is reported as being non-collaborative and lacking innovation, it naturally works in a collaborative way, necessary to deliver buildings. However, the authors state that innovation is stifled by "ineffective leadership, ingrained cultures, outdated technologies, poor logistics and lack of using solutions such as BIM" effectively. To enable change, "sustainable development must be seen as an opportunity for the construction industry, not as a cost." Matinaro and Liu [31] state that innovation management is not seen as important to construction companies because of practical and result-orientated ways of thinking, their main aim being to deliver buildings to client's briefs, within budget and to an agreed programme. An innovative organisational culture includes features such as knowledge sharing, tolerance of mistakes (viewed as learning opportunities) and good collaboration abilities, none of which are perceived strengths of the construction industry (ibid).

Loosemore and Richard [11] found that the economic dilemma of innovation in the construction industry stems from clients, who are unable and unwilling to provide scope and time in projects for innovation to happen. Reasons included: internal governance constraints; a lack of tools to value innovation in bids; a poor understanding of how built assets contribute to core business objectives and a narrow understanding of their central role in driving 
innovation. Therefore, innovation only tends to occur on large projects or with clients who procure multiple buildings. Most of the industry work with clients who procure buildings rarely, who want the lowest price for their investment and who do not recognise the building as a key long-term asset. Their research suggests that clients need to drive innovation and allow the construction industry to innovate, but the construction industry needs to educate clients to know this, to be aware of their role. The authors recognise that further research could explore the reasons why clients may find this difficult or be reluctant to adopt their recommendations (ibid). They refer to the McKell Institute Report into productivity in the Australian industry, written in 2012, which declares that firms must "innovate or perish" [41], a sentiment echoed by Farmer [42] in "Modernise or Die", recognising that the construction industry is always adapting and a large amount of innovation occurs, but the nature of the industry makes it challenging to make bold, obvious innovation within the industry due to its complexities [11].

\subsection{The move towards energy positive buildings}

In 1983 "Our Common Future" highlighted the important role buildings have to play in saving energy, stating that a low energy path is the best way to a sustainable future [43]. Consequently, there is a large amount of literature on "green" or sustainable buildings, some of which is summarised in this section.

Darko et al. [44] study drivers for implementing green building technologies. They find the top five drivers as being: energy-efficiency; reduced environmental impact; waterefficiency; occupants' health, comfort and satisfaction; and company image. Darko et al. [45] build on this initial research by undertaking a detailed literature review. Here, they identify "Government regulations and policies" as being the top driver. However, in a review of the barriers to green building adoption, Darko and Chan [40] found lack of green building codes and regulations is also seen as one of the barriers, although lack of information, cost, lack of incentives, lack of interest and demand, are also barriers listed.

Brejnrod et al. [46] describe a method to calculate the "absolute sustainability' of buildings, meaning that a buildings annual environmental burden is less than its share of the earth carrying capacity. One of the ways to reduce energy consumption was identified as reducing the impact intensity per energy unit, achieved by using renewable energy generation locally and by the public energy supply, which aligns with the energy positive case studies used in this research project. Meanwhile, Kosai and Tan [47] present a study of zero energy buildings from an energy trilemma perspective, finding that on-grid zero energy buildings with renewable energy delivered a better performance than off-grid zero energy buildings also aligning with energy positive buildings developed as part of this research project. Roaf and Nichol [48] advocate a change in design thinking back to more environmentally adaptive design of buildings. The authors state that consideration of building performance by architects at an early stage in the design process does not happen in many modern buildings.

The research of Attia [49] is dominated by ideas of regenerative design, cradle to cradle design and biomimicry, for environmentally effective sustainable buildings. An integrated design process and design-bid-build procurement are key to delivering low-energy buildings at zero or little extra cost, whereas the traditional, linear approach leads to missed opportunities (ibid). Rasekh and McCarthy [50] showed that to be sustainable, it is essential to be innovative. The main challenges they found were capital cost uplift, knowledge about sustainable buildings, and the necessity for early engagement of contractors, echoing findings from other research described in this paper. 
While the research examined used different terminologies and focused on slightly different aspects of "green" buildings, the main thread is the same - that there is a need to reduce the amount of energy used by the built environment but, in order to address this, it is critical to understand the challenges and drivers for change.

\section{DISCUSSION}

The literature examined above, clearly points to a need for a different approach to enable collaboration and innovation in construction, to deliver energy positive buildings, highlighting many challenges the construction industry faces. A collaborative approach was shown to be effective on large, complex projects, but these are still highlighted as pilot examples and not the norm. Nor have they been shown to work on smaller projects. It is timely to examine this now as it is twenty years since Rethinking Construction [4] and the industry is fast approaching the targets set out in Construction 2025 [51]. The need for an innovative solution is becoming ever more pressing and there is a gap in knowledge around this, as the literature illustrates.

The literature review has helped to refine the aims and objectives of the research project and provided evidence that this research is needed and is appropriate at this moment in time (2018). The main aim of the project is to investigate a new approach to procuring energy positive buildings, that integrate renewable energy generation into the building fabric to reduce the energy consumption of buildings and associated carbon emissions while improving user comfort within buildings.

Several common factors that affect the ability for the construction industry to work collaboratively were identified in the literature. These include: trust, cost, fragmented nature, risk, clients, culture, traditional procurement, time, funding, size of firms, communication, technology, lack of information and regulations; all of which need to be addressed to improve the overall performance of the industry and to enable innovation in construction, particularly to enable energy positive buildings. The first author proposes that energy positive buildings, such as those designed by the first author (see Fig. 1 above), which include innovative elements and are delivered in a collaborative way, could address many of the challenges facing the construction industry, as well as global challenges to reduce energy use in the built environment.

\section{CONCLUSIONS}

From the literature examined, there is strong evidence of links between collaboration, innovation and energy positive buildings, which address global environmental issues, suggesting that creating energy positive buildings in a collaborative way using innovative techniques and technologies could help transform construction.

Some research has explored the use of manufacturing techniques for lean construction, but there is room for further research in this area to aid the use of innovative sustainable techniques and technologies in construction. Whereas the challenges, drivers and barriers to innovation in construction are well documented, no clear solution has been identified within the literature. While collaborative working and innovation are identified as necessary to enable an energy efficient built environment and that such an environment is essential to addressing environmental, economic and social concerns, perceived costs, lack of knowledge and procurement methods appear to be the main barriers. There is a belief that enabling delivery of energy positive buildings through innovation and a collaborative process should be client-led. The way the client deals with procurement affects the entire construction process, including the degree of integration and cooperation between the project team [27]. 
These findings suggest the gap in knowledge is in finding a way to successfully implement collaborative working and innovation in one-off projects and to educate clients in how this approach could benefit them in the long term, providing a strong evidence base for the first author's research project. The case studies shown in Fig. 1 will aid this education process, through engagement with construction industry stakeholders. Further work will describe the next stage of this project which involves collecting data on the case studies.

\section{ACKNOWLEDGEMENTS}

The first author wishes to acknowledge support of the European Regional Development Fund through the Welsh Government in addition to Innovate UK and EPSRC, all of whom contribute funding to SPECIFIC. She would also like to thank her supervisors for their time and efforts in assisting the writing of this paper.

\section{REFERENCES}

[1] SPECIFIC, The SPECIFIC story. www.specific.eu.com/assets/downloads/casestudy/ The_SPECIFIC_Story_FINAL.pdf. Accessed on: 21 Oct. 2017.

[2] Laski, J. \& Burrows, V., From thousands to billions: Co-ordinated action towards $100 \%$ net zero carbon buildings by 2050 . www.worldgbc.org/news-media/ thousands-billions-coordinated-action-towards-100-net-zero-carbon-buildings- 2050 .

Accessed on: 22 Jun. 2017.

[3] Latham, M., Constructing the team. HMSO. http://constructingexcellence.org.uk/wpcontent/uploads/2014/10/Constructing-the-team-The-Latham-Report.pdf. Accessed on: 18 Mar. 2018.

[4] Egan, J., Rethinking construction. HMSO. http://constructingexcellence.org.uk/wpcontent/uploads/2014/10/rethinking_construction_report.pdf. Accessed on: 18 Mar. 2018.

[5] Ball, D. \& Fortune, C., Building project procurement process and the development of environmentally friendly housing schemes. Presented at 16th Annual ARCOM Conference. 6-8 Sep. 2000, Glasgow Caledonian University. Association of Researchers in Construction. Management, 1, 271-279. www.arcom.ac.uk/-docs/ proceedings/ar2000-271-279_Ball_and_Fortune.pdf. Accessed on: 24 Mar. 2018.

[6] Bresnan, M. \& Marshall, N., Understanding the diffusion and application of new management ideas in construction. Engineering, Construction and Architectural Management, 8(5/6), pp. 335-345, 2001. DOI: 10.1108/eb021194.

[7] Harrington, H.J., Voehl, F. \& Wiggin, H., Applying TQM to the construction industry. The TQM Journal, 24(4), pp. 352-362, 2012. DOI: 10.1108/17542731211247373.

[8] Challender, J., Farrell, P. \& Sherratt, F., Collaborative procurement: an exploration of practice and trust in times of austerity. Proceedings of the 29th Annual ARCOM Conference, 2-4 September 2013, Reading, UK, Association of Researchers in Construction Management, eds. S.D. Smith \& D.D. AhiagaDagbui, pp. 827-836, 2013.

[9] Ey, W., Zuo, J. \& Han, S. Barriers and challenges of collaborative procurements: An exploratory study. International Journal of Construction Management, 14(3), pp. 148155, 2014. DOI: 10.1080/15623599.2014.922725.

[10] Lloyd-Walker, B.M., Mills, A.J. \& Walker, D.H.T., Enabling construction innovation: the role of a no-blame culture as a collaboration behavioural driver in project alliances. Construction Management and Economics, 32(3), pp. 229-245, 2014.

DOI: $10.1080 / 01446193.2014 .892629$. 
[11] Loosemore, M. \& Richard, J., Valuing innovation in construction and infrastructure: Getting clients past a lowest price mentality. Engineering, Construction and Architectural Management, 22(1), pp. 38-53, 2015. DOI: 10.1108/ecam-02-20140031.

[12] Mesa, H.A., Molenaar, K.R. \& Alarcon, L.F., Exploring performance of the integrated project delivery process on complex building projects. International Journal of Project Managementm, 34(7), pp. 1089-1101, 2016. DOI: 10.1016/j.ijproman.2016.05.007.

[13] Garvey, R. \& McDermott, P., Delivering a systems-change model to address the paradox of changing construction. International Research Conference 2017: Shaping Tomorrow's Built Environment, pp. 675-684, 2017.

[14] Awuzie, B., Farag, F. \& McDermott, P., Achieving social value through construction frameworks: the effect of client attributes. Proceedings of the Institution of Civil Engineers - Management, Procurement and Law, 171(1), pp. 25-31, 2018. DOI 10.1680/jmapl.17.00009.

[15] Matthews, J., Love, P.E.D., Mewburn, J., Stobaus, C. \& Ramanayaka, C., Building information modelling in construction: insights from collaboration and change management perspectives. Production Planning and Control, 29(3), pp. 202-216, 2017. DOI: $10.1080 / 09537287.2017 .1407005$.

[16] Hairstans, R. \& Smith, R., Offsite HUB (Scotland): establishing a collaborative regional framework for knowledge exchange in the UK. Architectural Engineering and Design Management. 14(1-2), pp. 60-77, 2017.

DOI: $10.1080 / 17452007.2017 .1314858$.

[17] Wolstenholme, A., Never Waste a Good Crisis: A Review of Progress since Rethinking Construction and Thoughts for our Future. Constructing Excellence in the built environment. http://constructingexcellence.org.uk/wp-content/uploads/2014/12/ Wolstenholme_Report_Oct_2009.pdf. Accessed on: 18 Mar. 2018.

[18] Constructing Excellence, Collaborative procurement. http://constructingexcellence.org.uk/wp-content/uploads/2015/01/Collaborative Procurement_Guide.pdf. Accessed on: 17 Apr. 2018.

[19] Alencastro, J., Fuertes, A. \& de Wilde, P., Delivering energy-efficient social housing: implications of the procurement process. Procedia Engineering, 182, pp. 10-17, 2016. DOI: 10.1016/j.proeng.2017.03.103.

[20] Eriksson, P.E., Procurement strategies for enhancing exploration and exploitation in construction projects. Journal of Financial Management of Property and Construction, 22(2), pp. 211-230, 2017.

[21] RIBA Enterprises Ltd, National construction contracts and law survey 2015. www.thenbs.com/knowledge/national-construction-contracts-and-law-survey-2015. Accessed on: 24 Mar. 2018.

[22] Dulaimi, M.F., Ling, F.Y.Y., Ofori, G. \& de Silva, N., Enhancing integration and innovation in construction. Building Research and Information, 30(4), pp. 237-247, 2010.

[23] Anon, Innovative housing programme. http://gov.wales/topics/housing-andregeneration/housing-supply/innovative-housing-programme/?lang=en. Accessed on: 17 Apr. 2018.

[24] Pitts, M., Meet the industrial strategy challenge director - transforming construction. https://innovateuk.blog.gov.uk/2018/03/22/meet-the-industrial-strategy-challengedirector-transforming-construction/. Accessed on: 17 Apr. 2018. 
[25] Kilinc, N., Ozturk, G.B. \& Yitmen, I., The changing role of the client in driving innovation for design-build projects: Stakeholders' perspective. Procedia Economics and Finance, 21, pp. 279-287, 2015. DOI: 10.1016/s2212-5671(15)00178-1.

[26] Naoum, S. \& Egbu, C., Critical review of procurement method research in construction journals. Procedia Economics and Finance, 21, pp. 6-13, 2015. DOI: 10.1016/s22125671(15)00144-6.

[27] Eriksson, P.E. \& Westerberg, M., Effects of cooperative procurement procedures on construction project performance: A conceptual framework. International Journal of Project Management, 29(2), pp. 197-208, 2010.

DOI: $10.1016 / j$.ijproman.2010.01.003.

[28] Quirk, V., A brief history of BIM. www.archdaily.com/302490/a-brief-history-of-bim. Accessed on: 1 Jul. 2017.

[29] Davidson, S., What is BIM? www.rics.org/uk/knowledge/glossary/bim-intro/. Accessed on: 17 Apr. 2018.

[30] Shibeika, A. \& Harty, C., Diffusion of digital innovation in construction: a case study of a UK engineering firm. Construction Management and Economics, 33(5-6), pp. 453-466, 2015. DOI: 10.1080/01446193.2015.1077982.

[31] Matinaro, V. \& Liu, Y., Towards increased innovativeness and sustainability through organizational culture: A case study of a Finnish construction business. Journal of Cleaner Production, 142, pp. 3184-3193, 2017. DOI: 10.1016/j.jclepro.2016.10.151.

[32] Edie.Insight, Sector insight: The state of the sustainability in construction. https://edienet.s3.amazonaws.com/downloads/4227_edie_sector_insight_sustainabilit y_construction_v5.pdf. Accessed on: 4 Apr. 2018.

[33] Alwan, Z., Jones, P. \& Holgate, P., Strategic sustainable development in the UK construction industry, through the framework for strategic sustainable development, using building information modelling. Journal of Cleaner Production, 140, pp. 349358, 2017. DOI: 10.1016/j.jclepro.2015.12.085.

[34] Chevin, D., Interview: Jon Moorhouse, small practice punches above its weight. www.bimplus.co.uk/people/bim-allows-small-practice-punch-above-its-weight/. Accessed on: 6 Jul. 2018.

[35] Salem, O., Solomon, J., Genaidy, A \& Minkarah, I., Lean construction: From theory to implementation. Journal of Management in Engineering, 22(4), pp. 168-175, 2006.

[36] Peansupap, V. \& Walker, D., Exploratory factors influencing information and communication technology diffusion and adoption within Australian construction organisations: a micro analysis. Construction Innovation, 5, pp. 135-157, 2005. DOI: $10.1108 / 14714170510815221$.

[37] Ajayi, S.O. et al., Reducing waste to landfill: A need for cultural change in the UK construction industry. Journal of Building Engineering, 5, pp. 185-193, 2016. DOI: 10.1016/j.jobe.2015.12.007.

[38] Kotter, J., Leading Change, Harvard Business Review Press: Boston, 2012.

[39] Mousa, A., A business approach for transformation to sustainable construction: an implementation on a developing country. Resources, Conservation and Recycling, 101, pp. 9-19, 2015. DOI: 10.1016/j.resconrec.2015.05.007.

[40] Darko, A. \& Chan, A.P.C., Review of barriers to green building adoption. Sustainable Development, 25(3), pp. 167-179, 2016. DOI: 10.1002/sd.1651.

[41] Green, R., Toner, P. \& Agarwal, R., Understanding Productivity - Australia's Choice. https://mckellinstitute.org.au/app/uploads/The-McKell-Institute-UnderstandingProductivity-Australias-Choice-November-2012.pdf. Accessed on: 6 Jul. 2018. 
[42] Farmer, M. 2016. The Farmer Review of the UK Construction Labour Model: Modernise or Die. Construction Leadership Council. www.constructionleadershipcouncil.co.uk/wp-content/uploads/2016/10/FarmerReview.pdf. Accessed on: 24 Oct. 2016.

[43] Brundtland, G.H., Our Common Future, Oxford University Press, 1983.

[44] Darko, A., Chan, A.P.C., Owusu-Manu, D. \& Ameyaw, E.E., Drivers for implementing green building technologies: An international survey of experts. Journal of Cleaner Production, 145, pp. 386-394, 2016. DOI: 10.1016/j.jclepro.2017.01.043.

[45] Darko, A., Zhang, C. \& Chan, A.P.C., Drivers for green building: A review of empirical studies. Habitat International, 60, pp. 34-49, 2017.

[46] Brejnrod, K.N., Kalbar, P., Petersen, S. \& Birkved, M., The absolute environmental performance of buildings. Building and Environment, 119, pp. 87-98, 2017. DOI: 10.1016/j.buildenv.2017.04.003.

[47] Kosai, S. \& Tan, C., Quantitative analysis on a zero energy building performance from energy trilemma perspective. Sustainable Cities and Society, 32, pp. 130-141, 2017. DOI: $10.1016 /$ j.scs.2017.03.023.

[48] Roaf, S. \& Nichol, F., Running buildings on natural energy: Design thinking for a different future. Architectural Science Review, 60(3), pp. 145-149, 2017. DOI: 10.1080/00038628.2017.1303924.

[49] Attia, S., Towards regenerative and positive impact architecture: A comparison of two net zero energy buildings. Sustainable Cities and Society, 26, pp. 393-406, 2016.

[50] Rasekh, H. \& McCarthy, T., Delivering sustainable building projects - Challenges, reality and success. Journal of Green Building, 11(3), pp. 143-161, 2016.

[51] HM Government, Construction 2025: industrial strategy: government and industry in partnership. department for business, innovation and skills. www.gov.uk/ government/publications/construction-2025-strategy. Accessed on: 17 Feb. 2015. 